\title{
Progress and Challenges in the Understanding of Chronic Urticaria
}

\author{
Marta Ferrer, MD, PhD and Allen P. Kaplan, MD
}

\begin{abstract}
Chronic urticaria is a skin disorder characterized by transient pruritic weals that recur from day to day for 6 weeks or more. It has a great impact on patients' quality of life. In spite of this prevalence and morbidity, we are only beginning to understand its physiopathology and we do not have a curative treatment. Moreover, a patient with chronic urticaria may undergo extensive laboratory evaluations seeking a cause only to be frustrated when none is found. In recent years there have been significant advances in our understanding of some of the molecular mechanisms responsible for hive formation. The presence and probable role of IgG autoantibodies directed against epitopes expressed on the alpha-chain of the IgE receptor and to lesser extent, to IgE in a subset of patients is generally acknowledged. These autoantibodies activate complement to release C5a, which augments histamine release, and IL4 and leukotriene C4 are released as well. A perivascular cellular infiltrate results without predominance of either Th1 or Th2 lymphocyte subpopulations. Basophils of all chronic urticaria patients (autoimmune or idiopathic) are hyperresponsive to serum, regardless of source, but poorly responsive to anti IgE. In this review we will summarize the recent contributions to this field and try to provide insights to possible future directions for research on this disease.
\end{abstract}

Key words: autoimmunity, basophils, chronic urticaria, cotinine, IgE receptor, mast cells

C hronic urticaria is a skin disorder characterized by transient pruritic weals that recur from day to day for 6 weeks or more. We recently calculated a $0.6 \%(95 \%$ confidence interval $0.4-0.8$ ) prevalence in a population study. ${ }^{1}$ It has a great impact on patients' quality of life, ${ }^{2,3}$ to a degree equal to that experienced by sufferers from triple-vessel coronary artery disease.

In spite of this prevalence and morbidity, we are only beginning to understand its physiopathology and do not have a curative treatment. Moreover, a patient with chronic urticaria may undergo extensive laboratory evaluations seeking a cause, only to be frustrated when none is found.

The presence of antithyroid antibodies and early observations regarding a 5 to $10 \%$ incidence of functional

Marta Ferrer: Department of Allergy, Clinica Universitaria, Universidad de Navarra, Pamplona, Spain; Allen P. Kaplan: National Allergy, Asthma, and Urticaria Centers of Charleston, Charleston, South Carolina.

This work was funded by a grant from the Fondo de Investigacion Sanitaria, \#03/0789.

Correspondence to: Dr. Marta Ferrer, Department of Allergy and Clinical Immunology, Clinica Universitaria, Universidad de Navarra, Pio XII, 36, 31008-Pamplona, Spain; e-mail: mferrerp@unav.es.

DOI 10.2310/7480.2006.00016 anti-immunoglobulin (Ig)E antibodies suggested that autoimmunity might have a role. ${ }^{4,5}$ Hide et al corroborated the occasional presence of $\operatorname{IgG}$ anti-IgE and demonstrated the presence of functional autoantibodies against the alpha subunit of the $\operatorname{IgE}$ receptor in at least one-third of patients. ${ }^{6}$ These antibodies cause the release of histamine and other mediators that are responsible for urticaria and angioedema by activating blood basophils and cutaneous mast cells. ${ }^{7,8}$ The functional activity of the autoantibodies is augmented in the presence of components of the classic complement cascade, ${ }^{9}$ with a critical role for $\mathrm{C} 5 \mathrm{a} .{ }^{10}$

The presence of functional antibody can be verified either by the autologous skin test ${ }^{11}$ or by the ability of serum to degranulate basophils and mast cells. The basophil histamine release assay appears to be the "gold standard" for detecting functional autoantibodies in the serum of patients with chronic urticaria since we found both false-negative and false-positive results by binding assays. ${ }^{10,12}$ Thus, there were sera that had positive results for anti-alpha subunit antibody by means of immunoblotting that were not capable of inducing any measurable histamine release from human basophils. When we assayed a large group of patients' sera by both basophil histamine release and immunoblot, the results did not correlate when individual patients were assessed. ${ }^{13}$ The reason for this 
discrepancy is not clear. Although a cross-reaction of the alpha subunit with tetanus toxoid was reported, ${ }^{14}$ we could not absorb the immunoblot band with tetanus toxoid (unpublished observations, 1997). Furthermore, the presence of natural anti-alpha antibodies in the sera of healthy donors has been reported, ${ }^{15}$ which might become pathogenic depending on the state of occupancy of the Fce receptor by its natural ligand IgE. Horn and colleagues proposed that an imbalance between FceR $1 \alpha$ occupancy and natural anti-FceR $1 \alpha$ antibodies may be implicated in the pathogenesis of autoimmune urticaria. ${ }^{16}$

On the other hand, when histamine release is performed by incubating chronic urticaria sera with the basophils of normal donors, the percentage that is positive is 40 to $45 \%$. Approximately $60 \%$ of patients' sera are negative, and these remain idiopathic. The pathogenic mechanisms causing urticaria in these residual $60 \%$ of patients remain unknown. ${ }^{13}$ Sabroe and colleagues compared functional and nonfunctional sera and found that sera that were unable to activate basophils were not able to activate mast cells either. ${ }^{17}$ Thus, their lack of activity is not caused by unresponsive basophils. The only difference found was that those patients with functional antibodies had higher severity scores and more intense inflammation on skin biopsy.

Preincubation with interleukin (IL)-3 augments the histamine release without affecting the percentage of positive sera. ${ }^{18}$ More recently, it was demonstrated that some patients with chronic urticaria have IgG antibodies against the eosinophil low-affinity IgE receptor (CD23), which activate eosinophils and induce histamine release by eosinophie cationic protein (ECP), major basic protein (MBP), or other eosinophil cationic proteins. ${ }^{19}$ However, this has not yet been confirmed.

Autoimmunity is also supported by other observations. A higher frequency of human leukocyte antigen (HLA) class DR4 and DQ8 alleles is seen in patients with chronic urticaria, consistent with a genetic predisposition to this disease. $^{20}$

\section{IL-4 Production from Mast Cells and Basophils on Sera Stimulation}

We found that IL-4 was higher in the sera of patients with chronic urticaria (as well as atopic subjects) compared with controls, whereas IL-5 and interferon (IFN)- $\gamma$ levels were normal.

When we stimulated basophils from normal donors with the sera of chronic urticaria patients, we observed that those patients whose sera were able to activate basophils and induce histamine release were also able to induce IL-4 production. In contrast, sera that were negative for histamine release were unable to release IL-4 after incubation with basophils. Thus, the capacity to stimulate basophils to produce IL-4 was associated with the presence of histamine-releasing autoantibodies. When we stimulated mast cells, histamine, leukotrienes, and IL-4 were produced, and activation of mast cells by chronic urticaria sera was closely correlated with the ability to activate basophils. ${ }^{21}$

These observations agree with the study reported by Yasnowsky and colleagues, who found CD203c expression on incubation of basophils with chronic urticaria sera. This expression correlated with basophil histamine release. $^{22}$

Our data lend further support to the presence of basophil and cutaneous mast cell activators, predominantly anti-FceRI, in the sera of patients with chronic urticaria and demonstrate that such sera can lead to the production of leukotrienes and IL-4 in addition to histamine.

Our results also provide clues to explain the presence of a perivascular cellular infiltrate that differentiates chronic urticaria from other types of urticaria, such as dermatographism. ${ }^{23,24}$ The serum factor is responsible not only for histamine release but also C5a, cytokines, and, presumably, chemokines, all of which contribute to the recruitment of cells. ${ }^{25,26}$ The infiltrate resembles that seen in the allergic late-phase response but is different when examined closely. ${ }^{27}$ The $\mathrm{T}$ lymphocytes are a combination of $\mathrm{T}$ helper (Th)1 and Th 2 subtypes, and neutrophils and monocytes are more prominent in the lesions of chronic urticaria than in the late-phase response.

\section{Cytokine Production after Stimulation with PMA-Ionomycin: Phenotypic Characterization of the Cytokine-Producing Subpopulation}

We next questioned to what degree the sera of patients with chronic urticaria reflect the predominance of a Th1 or Th2 phenotype. We examined cytokine expression at the single-cell level ${ }^{28}$ and identified the T-cell subpopulations involved employing anticytokine monoclonal antibodies and flow cytometry. Thus, we could assess the simultaneous production of different cytokines in the same cell.

We stimulated lymphocytes from patients suffering from chronic urticaria and lymphocytes from control donors with phorbol 12 myristate 13 acetate (PMA)- 
ionomycin and found that $\mathrm{CD}^{+}$lymphocytes from patients with chronic urticaria produced significantly higher amounts of IL-4 and IFN- $\gamma$ than healthy donor lymphocytes. There was no difference in IL- 4 or IFN- $\gamma$ production by $\mathrm{CD}^{+}$lymphocytes of patients versus controls. We did not find significant differences when comparing the ratio of IFN- $\gamma$ to IL- 4 production by $\mathrm{CD} 4^{+}$ or $\mathrm{CD}^{+}$lymphocytes of control subjects and urticaria patients. ${ }^{21}$

These data strengthen previous studies suggesting an immune basis for chronic urticaria since we demonstrate that the $\mathrm{CD} 4^{+}$lymphocytes of patients with this disease are activated (or primed) and release greater amounts of cytokines employing a nonspecific stimulus. This finding is consistent with the histology found in biopsies of chronic urticaria lesions, where a $\mathrm{CD} 4^{+}$predominant infiltrate is found. ${ }^{29}$

Although PMA-I-induced activation is not a physiologic stimulus, previous studies indicate that the cytokine phenotype reflects the physiologic potential for cellular cytokine production. The cytokine profile found in our study does not reflect either a Th1 or a Th2 predominance. This conclusion is similar to that of a study in which the authors analyzed skin biopsies of chronic urticaria patients by in situ hybridization. IL-4, IL-5, and IFN- $\gamma$ probes revealed higher cytokine messenger ribonucleic acid expression in chronic urticaria patients than in healthy controls, without a predominance of either a Th1 or a Th2 profile. The cellular infiltrate associated with chronic urticaria was interpreted to represent either a Th0 profile ${ }^{27}$ or a mixture of activated Th1 and Th2 cells.

\section{Study on Releasability of Chronic Urticaria Basophils}

However, $60 \%$ of patients with chronic urticaria lacking any detectable autoantibody (or other serologic abnormality), who are designated "idiopathic" ${ }^{30}$ since no alternative etiology has been found, remain. We therefore compared the basophils of chronic urticaria patients with the basophils derived from normal donors, hoping to identify a basophil abnormality that might distinguish patients with idiopathic urticaria from patients with autoimmune urticaria.

A basophil abnormality is of particular interest because some patients with chronic urticaria have basopenia ${ }^{31}$ and hyporesponsiveness to anti-IgE suggested by in vivo desensitization. ${ }^{32}$ For that purpose, we examined the response of basophils of healthy donors, atopic donors, and patients with chronic urticaria to a variety of stimuli, including anti-IgE, bradykinin, ${ }^{33}$ monocyte chemotactic protein (MCP)-1, ${ }^{34} \mathrm{C} 5 \mathrm{a},{ }^{9,10,35}$ and serum.

Our data ${ }^{36}$ support previous reports indicating that the basophils of patients have a diminished response to anti-IgE $E^{37-39}$ and, to a lesser degree, to C5a. No differences were observed when the basophils from patients were incubated with bradykinin or MCP- $1 .^{36}$ These results are not due to a variation in histamine content since we did not find significant differences between healthy control and urticaria basophils. We did, however, observe higher total histamine content and spontaneously released histamine when the basophils of atopic subjects were compared with the basophils of healthy controls or patients with chronic urticaria. These results are consistent with those published by Wahn and Zuberbier and their colleagues. ${ }^{40,41}$

Although the basophils of chronic urticaria patients seem to be less responsive to stimuli, such as anti-IgE or C5a, which act through different receptors, the abnormality does not seem to be due to a general impairment of signaling since chronic urticaria basophils respond normally to other stimuli that act independently from the $\operatorname{IgE}$ receptor, such as A23187, formyl-met-leu-phe (FMLP), and platelet-activating factor, ${ }^{41}$ in addition to bradykinin ${ }^{33}$ and MCP-1. ${ }^{42}$

\section{Hyperresponsiveness of Chronic Urticaria Basophils When Incubated with Sera}

Surprisingly, we observed prominent histamine release when the basophils of chronic urticaria patients were stimulated with other sera regardless of the source. Thus, striking histamine release was obtained with sera derived from patients with chronic idiopathic urticaria or chronic autoimmune urticaria or even with normal control sera.

These results indicate that the basophils of chronic urticaria patients are more responsive to some constituent of serum regardless of the source. Basophils derived from patients with chronic idiopathic urticaria were just as abnormal as basophils from patients with chronic autoimmune urticaria. Both groups of basophil were equally responsive to bradykinin, C5a, MCP-1, or serum. ${ }^{36}$ Both groups were also hyporesponsive to anti-IgE; thus, in vivo desensitization owing to the presence of an autoantibody does not seem to be the explanation.

Hence, chronic urticaria basophils, in spite of being less responsive to some stimuli, are clearly highly responsive when incubated with sera, even normal sera. One could argue that this effect might be due to variability in donor basophil histamine release; however, our study employed 
the same basophil preparation incubated with different stimuli. When different basophil preparations were compared, the counts were similar, and the results were strikingly consistent for all of the chronic urticaria basophils studied.

\section{Conclusion}

Chronic urticaria is now divided into the autoimmune and idiopathic subgroups. Autoimmunity is dependent on the presence of IgG antibody to the alpha subunit of the IgE receptor and, to a lesser degree, anti-IgE. Such sera release histamine, leukotrienes, and IL-4 from donor basophils. However, stimulation of T lymphocytes releases both IL-4 and IFN- $\gamma$, and the histology of biopsy specimens does not have a predominance of Th1 or Th2 subtypes, although most cells are $\mathrm{CD} 4^{+}$rather than $\mathrm{CD} 8^{+}$.

Chronic urticaria basophils have several specific features that distinguish them from the basophils of healthy donors or atopic controls. They are less responsive to anti-IgE and $\mathrm{C} 5 \mathrm{a}$, with no difference when stimulated with bradykinin and MCP-1, and have much higher release when incubated with serum. The factor in serum that stimulates these cells has not been identified, nor is the abnormal responsiveness of the cells understood. One study has, however, suggested a signal abnormality involving Ras in chronic urticaria basophils. ${ }^{43}$ The other known basophil abnormality in chronic urticaria is basopenia. ${ }^{31,44}$

Although 55\% of chronic urticaria patients are still considered idiopathic since the etiology is obscure, including the absence of autoantibodies, this is the first demonstration that the basophils of this group share abnormal responsiveness with the basophils of patients with chronic autoimmune urticaria, just as the histology of the two groups is strikingly similar. ${ }^{27,45}$

All of these findings provide a basis for further investigation of the pathogenesis and treatment of this disease. $^{46-48}$

\section{References}

1. Gaig P, Olona M, Muñoz Lejarazu D, et al. Epidemiology of urticaria in Spain. J Invest Allergol Clin Immunol 2004;14:342-5.

2. O'Donnell BF, Lawlor F, Simpson J, et al. The impact of chronic urticaria on the quality of life. Br J Dermatol 1997;136:197-201.

3. Grob JJ, Gaudy-Marqueste C. Urticaria and quality of life. Clin Rev Allergy Immunol 2006;30:47-51.

4. Leznoff A, Josse RG, Denburg J, Dolovich J. Association of chronic urticaria and angioedema with thyroid autoimmunity. Arch Dermatol 1983;119:636-40.
5. Gruber BL, Baeza ML, Marchese MJ, et al. Prevalence and functional role of anti-IgE autoantibodies in urticarial syndromes. J Invest Dermatol 1988;90:213-7.

6. Hide M, Francis DM, Grattan CE, et al. Autoantibodies against the high-affinity IgE receptor as a cause of histamine release in chronic urticaria. N Engl J Med 1993;328:1599-604.

7. Niimi N, Francis DM, Kermani F, et al. Dermal mast cell activation by autoantibodies against the high affinity IgE receptor in chronic urticaria. J Invest Dermatol 1996;106:1001-6.

8. Ferrer M, Kinet JP, Kaplan AP. Comparative studies of functional and binding assays for IgG anti-Fc(epsilon)RIalpha (alphasubunit) in chronic urticaria. J Allergy Clin Immunol 1998;101: 672-6.

9. Ferrer M, Nakazawa K, Kaplan AP. Complement dependence of histamine release in chronic urticaria. J Allergy Clin Immunol 1999;104:169-72.

10. Kikuchi Y, Kaplan AP. A role for C5a in augmenting IgGdependent histamine release from basophils in chronic urticaria. J Allergy Clin Immunol 2002;109:114-8.

11. Sabroe RA, Grattan CE, Francis DM, et al. The autologous serum skin test: a screening test for autoantibodies in chronic idiopathic urticaria. Br J Dermatol 1999;140:446-52.

12. Fiebiger E, Hammerschmid F, Stingl G, Maurer D. AntiFcepsilonRIalpha autoantibodies in autoimmune-mediated disorders. Identification of a structure-function relationship. J Clin Invest 1998;101:243-51.

13. Kikuchi Y, Kaplan AP. Mechanisms of autoimmune activation of basophils in chronic urticaria. J Allergy Clin Immunol 2001;107: 1056-62.

14. Horn MP, Gerster TF, Ochensberger BF, et al. Human antiFcepsilonRIalpha autoantibodies isolated from healthy donors cross-react with tetanus toxoid. Eur J Immunol 1999;29:1139-48.

15. Pachlopnik JM, Horn MP, Fux $M$, et al. Natural antiFc[epsiv]RI[alpha] autoantibodies may interfere with diagnostic tests for autoimmune urticaria. J Autoimmun 2004;22:43-51.

16. Horn MP, Pachlopnik JM, Vogel M, et al. Conditional autoimmunity mediated by human natural anti-FceRIa autoantibodies? FASEB J 2001;15:2268-74.

17. Sabroe RA, Fiebiger E, Francis DM, et al. Classification of antiFcepsilonRI and anti-IgE autoantibodies in chronic idiopathic urticaria and correlation with disease severity. J Allergy Clin Immunol 2002;110:492-9.

18. Ferrer M, Luquin E, Kaplan AP. IL3 effect on basophils histamine release upon stimulation with chronic urticaria sera. Allergy 2003; 58:802-7.

19. Puccetti A, Bason C, Simeoni S, et al. In chronic idiopathic urticaria autoantibodies against FceRII/CD23 induce histamine release via eosinophil activation. Clin Exp Allergy 2005;35:1599_ 607.

20. O’Donnell BF, O’Neill CM, Francis DM, et al. Human leucocyte antigen class II associations in chronic idiopathic urticaria. Br J Dermatol 1999;140:853-8.

21. Ferrer M, Luquin E, Sanchez-Ibarrola A, et al. Secretion of cytokines, histamine and leukotrienes in chronic urticaria. Int Arch Allergy Immunol 2002;129:254-60.

22. Yasnowsky KM, Dreskin SC, Efaw B, et al. Chronic urticaria sera increase basophil CD203c expression. J Allergy Clin Immunol 2006;117:1430-4. 
23. Stewart GE. Histopathology of chronic urticaria. Clin Rev Allergy Immunol 2002;23:195-200.

24. Natbony SF, Phillips ME, Elias JM, et al. Histologic studies of chronic idiopathic urticaria. J Allergy Clin Immunol 1983;71:17783.

25. Hermes B, Prochazka AK, Haas N, et al. Upregulation of TNFalpha and IL-3 expression in lesional and uninvolved skin in different types of urticaria. J Allergy Clin Immunol 1999;103:30714.

26. Haas N, Toppe E, Henz BM. Microscopic morphology of different types of urticaria. Arch Dermatol 1998;134:41-6.

27. Ying S, Kikuchi Y, Meng Q, et al. TH1/TH2 cytokines and inflammatory cells in skin biopsy specimens from patients with chronic idiopathic urticaria: comparison with the allergen-induced late-phase cutaneous reaction. J Allergy Clin Immunol 2002;109: 694-700.

28. Openshaw P, Murphy EE, Hosken NA, et al. Heterogeneity of intracellular cytokine synthesis at the single-cell level in polarized T helper 1 and T helper 2 populations. J Exp Med 1995;182:135767.

29. Barlow RJ, Ross EL, MacDonald DM, et al. Mast cells and T lymphocytes in chronic urticaria. Clin Exp Allergy 1995;25:317-22.

30. Grattan CE, Sabroe RA, Greaves MW. Chronic urticaria. J Am Acad Dermatol 2002;46:645-57.

31. Grattan CE, Walpole D, Francis DM, et al. Flow cytometric analysis of basophil numbers in chronic urticaria: basopenia is related to serum histamine releasing activity. Clin Exp Allergy 1997;27:1417-24.

32. Plaut M, Kazimierczak W, Lichtenstein LM. Abnormalities of basophil "releasability" in atopic and asthmatic individuals. J Allergy Clin Immunol 1986;78:968-73.

33. Lawrence ID, Warner JA, Cohan VL, et al. Bradykinin analog induces histamine release from human skin mast cells. Adv Exp Med Biol 1989;247:225-9.

34. Alam R, Forsythe P, Stafford S, et al. Monocyte chemotactic protein-2, monocyte chemotactic protein-3, and fibroblastinduced cytokine. Three new chemokines induce chemotaxis and activation of basophils. J Immunol 1994;153:3155-9.

35. Fureder W, Agis H, Willheim M, et al. Differential expression of complement receptors on human basophils and mast cells. Evidence for mast cell heterogeneity and CD88/C5aR expression on skin mast cells. J Immunol 1995;155:3152-60.
36. Luquin E, Kaplan AP, Ferrer M. Increased responsiveness of basophils of patients with chronic urticaria to sera but hyporesponsiveness to other stimuli. Clin Exp Allergy 2005;35:456-60.

37. Kern F, Lichtenstein LM. Defective histamine release in chronic urticaria. J Clin Invest 1976;57:1369-77.

38. Bischoff SC, Zwahlen R, Stucki M, et al. Basophil histamine release and leukotriene production in response to anti-IgE and anti-IgE receptor antibodies. Comparison of normal subjects and patients with urticaria, atopic dermatitis or bronchial asthma. Int Arch Allergy Immunol 1996;110:261-71.

39. Greaves MW, Plummer VM, McLaughlan P, Stanworth DR. Serum and cell bound IgE in chronic urticaria. Clin Allergy 1974;4: 265-71.

40. Wahn U, Ernsting M, Peterson J. Spontaneous histamine release from washed leukocytes and whole blood in atopic and non-atopic individuals. Allergy 1990;45:109-14.

41. Zuberbier T, Schwarz S, Hartmann K, et al. Histamine releasability of basophils and skin mast cells in chronic urticaria. Allergy 1996; 51:24-8.

42. Alam R, Lett-Brown MA, Forsythe PA, et al. Monocyte chemotactic and activating factor is a potent histamine-releasing factor for basophils. J Clin Invest 1992;89:723-8.

43. Confino-Cohen R, Aharoni D, Goldberg A, et al. Evidence for aberrant regulation of the p21Ras pathway in PBMCs of patients with chronic idiopathic urticaria. J Allergy Clin Immunol 2002; 109:349-56.

44. Grattan CE, Dawn G, Gibbs S, Francis DM. Blood basophil numbers in chronic ordinary urticaria and healthy controls: diurnal variation, influence of loratadine and prednisolone and relationship to disease activity. Clin Exp Allergy 2003;33:337-41.

45. Sabroe RA, Poon E, Orchard GE, et al. Cutaneous inflammatory cell infiltrate in chronic idiopathic urticaria: comparison of patients with and without anti-FcepsilonRI or anti-IgE autoantibodies. J Allergy Clin Immunol 1999;103:484-93.

46. Marsland AM, Soundararajan S, Joseph K, Kaplan AP. Effects of calcineurin inhibitors on an in vitro assay for chronic urticaria. Clin Exp Allergy 2005;35:554-9.

47. O'Donnell BF, Barr RM, Black AK, et al. Intravenous immunoglobulin in autoimmune chronic urticaria. Br J Dermatol 1998;138: $101-6$.

48. Kessel A, Bamberger E, Toubi E. Tacrolimus in the treatment of severe chronic idiopathic urticaria: an open-label prospective study. J Am Acad Dermatol 2005;52:145-8. 